\title{
ANALISA REKAYASA SIFAT MEKANIK BAJA AISI 4140 DENGAN VARIASI SUHU TEMPERING UNTUK MENINGKATKAN KEULETAN DAN KEKERASAN MATERIAL
}

\author{
Shultoni Mahardika \\ ${ }^{1}$ Prodi Teknik Mesin, Fakultas Teknik Universitas Qomaruddin, Gresik \\ e-mail:*1mahardika89@uqgresik.ac.id
}

\begin{abstract}
Abstrak
Baja merupakan jenis material yang banyak digunakan sebagai bahan utama dalam pembuatan berbagai macam spare part mesin-mesin industri maupun otomatif. Beberapa sifat mekanis baja yang sering dipakai dalam perancangan yakni kekerasan, keuletan dan ketangguhan.. Seringkali dalam suatu perancangan, kita kesulitan mendapatkan baja dengan sifat mekanis yang sesuai dengan perancangan. Untuk itulah enginer melakukan rekyasa sifat mekanis, untuk mendapatkan baja yang sesuai dengan perhitungan perancangan. Baja AISI 4140 merupakan baja paduan menengah. Baja ini seringkali digunakan untuk material part mesin industri maupun otomotif. Penelitian ini merekayasa sifat mekanik baja tersebut, yakni kekerasan dan keuletan materialnya. Proses yang dilakukan yakni melakukan hardening baja pada suhu $850{ }^{\circ} \mathrm{C}$ yang diikuti pendinginan cepat dengan media air. Setelah itu dilakukan tempering pada suhu $300^{\circ} \mathrm{C}, 400^{\circ} \mathrm{C}$ dan $500^{\circ} \mathrm{C}$ dengan pendinginan bersamaan dengan tungku. Hasilnya kekerasan dan kekuatan tarik material mengalami peningkatan, jika dibandingkan dengan material tanpa perlakuan. Metode ini efektif digunakan untuk mendapatkan nilai kekuatan mekanis yang sesuai dengan perhitungan perencanaan teknik.
\end{abstract}

Kata kunci: Tempering, AISI 4140, Rekayasa Sifat Mekanik

\begin{abstract}
Steel is a type of material that is widely used as a main material in the manufacture of various kinds of industrial and automatic machinery spare parts. Some mechanical properties of steel that are often used in design are hardness, ductility and toughness. Often in a design, we have difficulty getting steel with mechanical properties that are appropriate with the design. For this reason, engineering carried out mechanical properties engineering, to obtain steel in accordance with design calculations. AISI 4140 steel is a medium alloy steel. This steel is often used for industrial and automotive machinery parts. This research engineered the mechanical properties of the steel, namely the hardness and ductility of the material. The process is carried out by conducting steel hardening at $850{ }^{\circ} \mathrm{C}$ followed by rapid cooling with water media. After that, tempering at temperatures of $300{ }^{\circ} \mathrm{C}, 400^{\circ} \mathrm{C}$ and $500^{\circ} \mathrm{C}$ by cooling together with the furnace. The result is hardness and tensile strength of the material has increased, when compared with untreated material. This method is effectively used to obtain mechanical strength values in accordance with technical planning calculations. .
\end{abstract}

Keywords: Tempering, AISI 4140, Mechanical Properties Engineering 


\section{PENDAHULUAN}

Baja merupakan jenis material yang banyak digunakan sebagai bahan utama dalam pembuatan berbagai macam spare part mesin-mesin industri maupun otomatif. Beberapa sifat mekanis baja yang sering dipakai dalam perancangan yakni kekerasan, keuletan dan ketangguhan. Sifat mekanis tersebut dapat kita lihat dengan mudah pada sertifikat material yang didapatkan saat membeli bahan untuk kebutuhan perancangan. Seringkali dalam suatu perancangan, kita kesulitan mendapatkan baja dengan sifat mekanis yang sesuai dengan perancangan. Untuk itulah enginer melakukan rekyasa sifat mekanis, untuk mendapatkan baja yang sesuai dengan perhitungan perancangan.

Baja AISI 4140 merupakan baja paduan menengah dengan komposisi kimia $\mathrm{C}(0.38-$ $0.43 \%)$, Mn (0.75-1.00 \%), Si (0.20-0.35 \%), Cr (0.80-1.10 \%), Mo (0.15-0.25\%), P $(\leq 0.035$ $\%)$ dan $\mathrm{S}(\leq 0.04 \%)[1]$. Baja ini umunya digunakan sebagai bahan baku pembuatan poros maupun gear. Paduan $\mathrm{Cr}$ dan Mo pada bahan, menyebabkan bahan mempunyai sifat tahan karat[2]. Kandungan Carbon pada bahan ini yakni 0.38-0.43\%, sehingga menggolongkan bahan ini pada Baja Hypotectoid. Prosentase Carbon digunakan dalam penentuan suhu pemanasan.

Proses tempering pada baja dilakukan dengan memanaskan kembali baja yang sebelumnya dikeraskan[3]. Dengan menggunakan proses ini maka keuletan baja dapat ditingkatkan, sedangkan kekerasan dan ketangguhan baja menurun. Proses ini diperlukan dalam proses perancangan untuk mendapatkan kombinasi yang tinggi antara kekuatan, keuletan dan ketangguhan. Sehingga struktur material yang dikehendaki dalam perancangan lebih stabil[4].

Dalam proses perlakukan panas, lama waktu penahanan menentukan perambatan panas yang sama antar sisi dari baja. Salah satu faktor dalam penentuan lama waktu penahanan, yakni bergantung pada bentuk dan dimensi baja. Semakin rumit bentuk dan dimensinya, semakin lama waktu penahannya. Hal ini diperlukan agar panas yang diterima baja sampai ke inti material.

Waktu yang diperlukan baja untuk mencapai temperatur ruang, juga menentukan hasil akhir dari struktur mikro baja. Salah satu cara untuk menentukannya yakni menggunakan diagram Continuos Cooling Transformations (CTT). Diagram tersebut digunakan untuk memperkirakan hasil akhir dari struktur mikro baja berdasarkan kecepatan waktu pendinginan. Dari diagram tersebut dapat kita ketahui bahwa, semakin cepat baja tersebut mencapai suhu ruang, maka mikro struktur yang terbentuk yakni martensit.

Semakin lama baja mencapai suhu ruang, maka mikro struktur yang terbentuk yakni ferrite + pearlite. Struktur martensit menyebabkan baja cenderung lebih keras dan getas, sedangkan struktur ferrite + pearlite menyebabkan baja cenderung lebih ulet dan melunak. Penelitian ini bertujuan untuk mengetahui pengaruh variasi temperatur tempering terhadap sifat mekanik baja dan strktur mikro akhir baja setelah perlakuan tersebut. Sifat mekanik yang ditinjau dalam penelitian ini yakni kekerasan dan kekuatan tarik.

\section{METODE PENELITIAN}

Tahapan penelitian yang kami lakukan dalam penelitian ini yakni sebagai berikut:

\subsection{Diagram Alir Penelitian}

Diagram alir yang digunakan dalam penelitian ini terdapat pada gambar 2.1. 


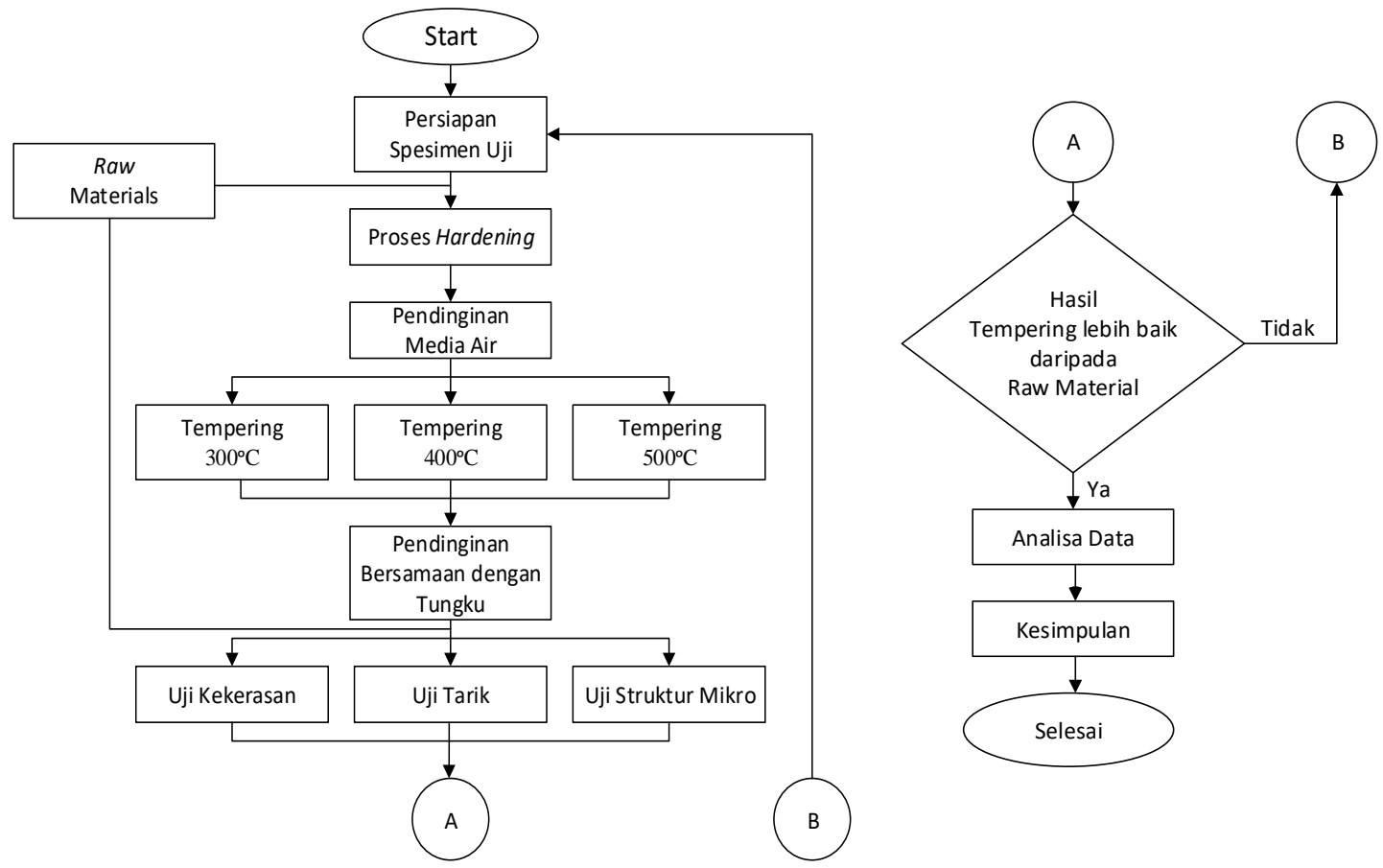

Gambar 2.1. Diagram Alir Penelitian

\subsection{Persiapan Spesimen Uji}

Spesimen uji yang digunakan dalam penelitian ini yakni baja karbon menengah AISI 4140. Baja tersebut dibentuk sesuai standar pengujian masing-masing. Untuk uji tarik, spesimen dibentuk berdasarkan standar JIS Z2201. Pengujian kekerasan dilakukan langsung pada spesimen yang telah mengalami uji tarik. Sedangkan mikro struktur dilakukan dengan membentuk spesimen menjadi pejal, berdiameter $10 \mathrm{~mm}$ dan tebal $20 \mathrm{~mm}$. Spesimen tersebut, kemudain dietsa dan diamplas sampai mengkilap.

\subsection{Proses Hardeninig}

Hardening dilakukan dalam furnace pada suhu $850^{\circ} \mathrm{C}$ dengan waktu penahanan 20 menit. Waktu penahanan ini sesuai dengan ketebalan spesimen, sehingga panas yang diterima baja sampai ke inti. Jika waktu penahanan terlalu pendek, maka panas tersebut tidak mencapai inti. Akibatnya, terjadi perbadaan mikro struktur antara permukaan spesimen dan inti spesimen. Setelah material dipanaskan kemudian dilakukan pendinginan cepat untuk menghasilkan struktur yang lebih keras daripada Raw Material.

\subsection{Proses Tempering}

Tempering dilakukan dengan memasukkan kembali material yang mengalami proses Hardening kedalam furnace untuk dipanaskan ulang sesuai suhu tempering. Suhu tempering yang dikenakan yakni $300^{\circ} \mathrm{C}, 400^{\circ} \mathrm{C}$ dan $500^{\circ} \mathrm{C}$. Waktu penahanan yang dilakukan pada masing-masing variasi suhu yakni 20 menit. Setelah proses tersebut dilakukan pendinginan didalam tungku sampai suhu ruang.

\section{HASIL DAN PEMBAHASAN}

\subsection{Pengujian Kekerasan}

Pengujian kekerasan dilakukan dengan menggunakan mesin uji kekerasan Universal Hardness Tester merek EMCO milik BLKI Surabaya dengan menggunakan metode pengujian Brinell. Spesimen yang digunakan sebagai data pembanding yakni spesimen uji tanpa perlakuan (Raw Material). Pada pengujian spesimen tanpa perlakuan didapatkan rata-rata kekerasan pada 
spesimen 1 adalah $194 \mathrm{HB}$, spesimen 2 sebesar 225 HB dan spesimen 3210 HB. Adapun ratarata kekerasan kelompok yakni 209,67 HB.

Spesimen yang mengalami perlakuan panas Tempering dengan suhu $300^{\circ} \mathrm{C}$, mendapatkan rata-rata kekerasan yakni pada spesimen 1 sebesar 322,67 HB, spesimen 2 sebesar 358,54 HB dan spesimen 3 sebesar 374,87 HB. Adapun rata-rata kekerasan kelompok Hardening yakni $352,02 \mathrm{HB}$. Spesimen yang mengalami perlakuan panas Tempering dengan suhu $400^{\circ} \mathrm{C}$, mendapatkan rata-rata kekerasan yakni pada spesimen 1 sebesar $273,57 \mathrm{HB}$, spesimen 2 sebesar 296,95 HB dan spesimen 3 sebesar 281,91 HB. Adapun rata-rata kekerasan kelompok Hardening yakni 284,14 HB. Spesimen yang mengalami perlakuan panas Tempering dengan suhu $500^{\circ} \mathrm{C}$, mendapatkan rata-rata kekerasan yakni pada spesimen 1 sebesar 233,88 $\mathrm{HB}$, spesimen 2 sebesar 248,62 HB dan spesimen 3 sebesar 247,18 HB. Adapun rata-rata kekerasan kelompok Hardening yakni 243,22 HB.

Dari data tersebut, dapat disimpulkan nilai rata-rata kelompok kekerasan baja AISI 4140 tanpa perlakuan sebesar $209,67 \mathrm{HB}$, nilai kekerasan setelah Tempering suhu $300^{\circ} \mathrm{C}$, yakni $352,02 \mathrm{HB}$, nilai kekerasan setelah Tempering suhu $400^{\circ} \mathrm{C}$ yakni $284,14 \mathrm{HB}$, dan nilai kekerasan setelah Tempering suhu $500^{\circ} \mathrm{C}$ yakni $243,22 \mathrm{HB}$. Grafik rata-rata hasil kekerasan dapat dilihat pada gambar 3.1. Pada pengujian baja yang telah mengalami perlakuan, terdapat kenaikan nilai kekerasan daripada Raw Material. Nilai kekerasan tertinggi adalah pada suhu tempering $300^{\circ} \mathrm{C}$ dan terendah pada suhu yang tempering paling tinggi $500^{\circ} \mathrm{C}$. Hal ini menggambarkan bahwa semakin tinggi suhu tempering maka mengurangi nilai kekerasan material hingga hampir mendekati nilai kekerasan tanpa perlakuan.

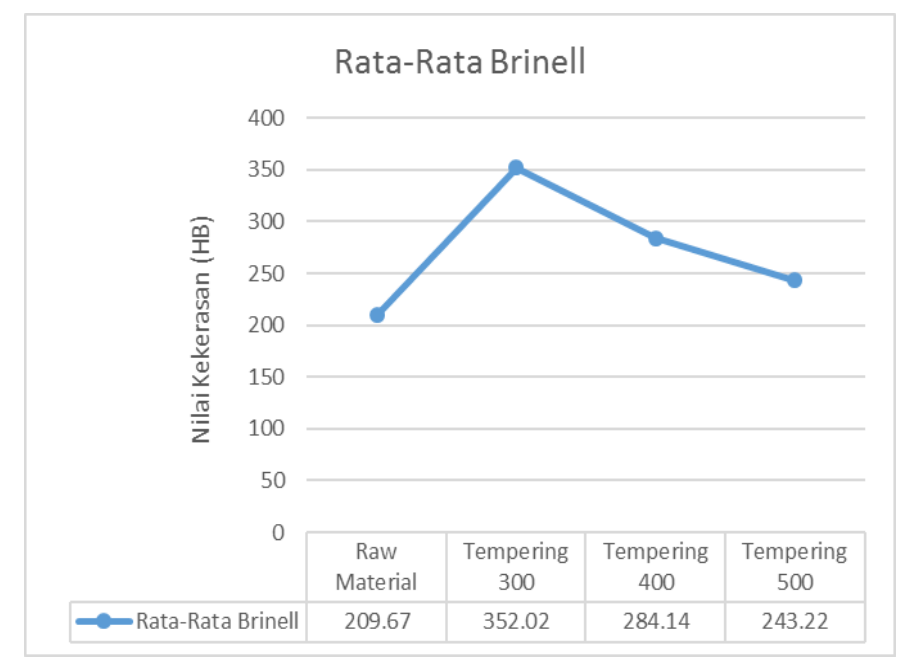

Gambar 3.1. Rata-Rata Kekerasan Brinell Baja AISI 4140

\subsection{Pengujian Kekuatan Tarik}

Pengujian Kekuatan Tarik dilakukan dengan menggunakan mesin uji tarik Universal Testing Machine merek Gotech milik BLK Surabaya. Spesimen yang digunakan sebagai data pembanding yakni spesimen uji tanpa perlakuan (Raw Material). Pada pengujian spesimen tanpa perlakuan didapatkan kekuatan tarik pada spesimen 1 adalah 70,53 Kgf $/ \mathrm{mm}^{2}$, spesimen 2 sebesar 71,24 Kgf $/ \mathrm{mm}^{2}$ dan spesimen 3 sebesar 70,89 Kgf $/ \mathrm{mm}^{2}$. Adapun rata-rata kekerasan kelompok yakni $70,88 \mathrm{Kgf} / \mathrm{mm}^{2}$.

Pada spesimen yang mengalami Tempering dengan suhu $300^{\circ} \mathrm{C}$ didapatkan data pengujian kekuatan tarik pada spesimen 1 adalah 77,80 Kgf/mm², spesimen 2 sebesar 77,80 $\mathrm{Kgf} / \mathrm{mm}^{2}$ dan spesimen 3 sebesar 79,46 Kgf $/ \mathrm{mm}^{2}$. Adapun rata-rata kekerasan kelompok yakni $78,35 \mathrm{Kgf} / \mathrm{mm}^{2}$. Pada spesimen yang mengalami Tempering dengan suhu $400^{\circ} \mathrm{C}$ didapatkan data pengujian kekuatan tarik pada spesimen 1 adalah $98,72 \mathrm{Kgf} / \mathrm{mm}^{2}$, spesimen 2 sebesar 97,76 $\mathrm{Kgf} / \mathrm{mm}^{2}$ dan spesimen 3 sebesar $96,48 \mathrm{Kgf} / \mathrm{mm}^{2}$. Adapun rata-rata kekerasan kelompok yakni $97,65 \mathrm{Kgf} / \mathrm{mm}^{2}$. Pada spesimen yang mengalami Tempering dengan suhu $500^{\circ} \mathrm{C}$ didapatkan 
data pengujian kekuatan tarik pada spesimen 1 adalah $117,51 \mathrm{Kgf} / \mathrm{mm}^{2}$, spesimen 2 sebesar $116,24 \mathrm{Kgf} / \mathrm{mm}^{2}$ dan spesimen 3 sebesar $115,46 \mathrm{Kgf} / \mathrm{mm}^{2}$. Adapun rata-rata kekerasan kelompok yakni $116,40 \mathrm{Kgf} / \mathrm{mm}^{2}$.

Dari data tersebut, dapat disimpulkan nilai rata-rata kekuatan tarik baja AISI 4140 tanpa perlakuan sebesar $70,88 \mathrm{Kgf} / \mathrm{mm}^{2}$, nilai kekuatan tarik setelah Tempering suhu $300^{\circ} \mathrm{C}$ yakni $78,35 \mathrm{Kgf} / \mathrm{mm}$, nilai kekuatan tarik setelah Tempering suhu $400^{\circ} \mathrm{C}$ yakni $97,65 \mathrm{Kgf} / \mathrm{mm}^{2}$, dan nilai kekuatan tarik setelah Tempering suhu $500^{\circ} \mathrm{C}$ yakni $116,40 \mathrm{Kgf} / \mathrm{mm}^{2}$. Grafik rata-rata hasil kekuatan tarik dapat dilihat pada gambar 3.2. Pada pengujian baja yang telah mengalami perlakuan, terdapat kenaikan nilai kekuatan tarik daripada Raw Material. Nilai kekuatan tarik tertinggi adalah pada suhu tempering $500^{\circ} \mathrm{C}$ dan terendah pada suhu yang tempering paling tinggi $300^{\circ} \mathrm{C}$. Hal ini menggambarkan bahwa semakin tinggi suhu tempering maka menambah kekuatan tarik Baja AISI 4140 material hingga menyebabkan material semakin ulet.

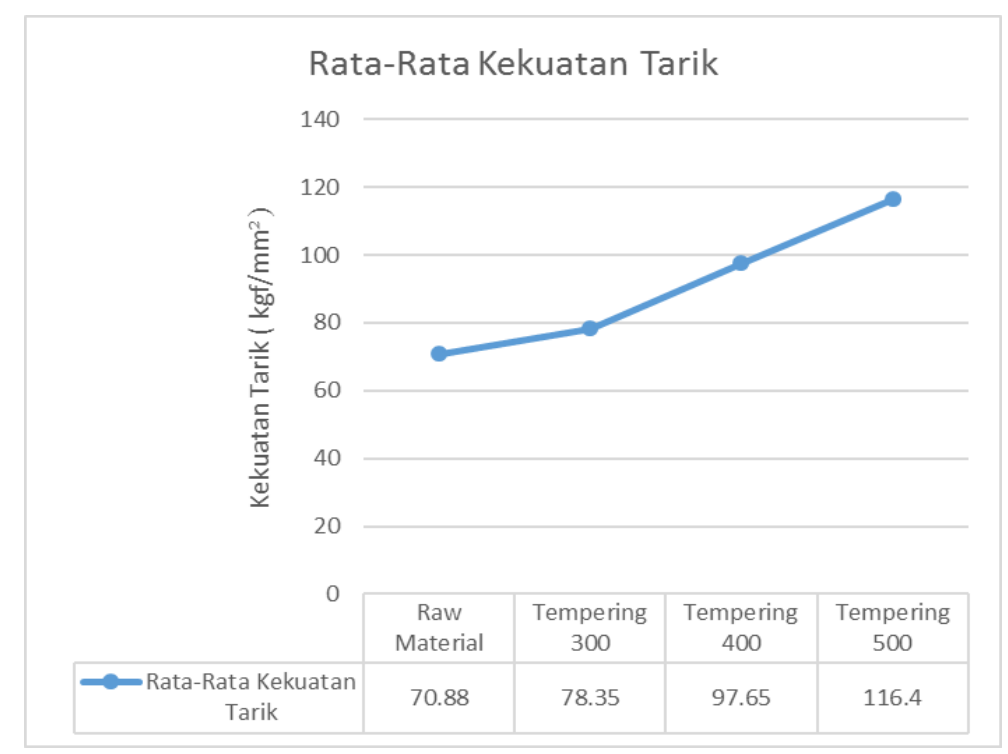

Gambar 3.2. Rata-Rata Kekuatan Tarik Baja AISI 4140

\subsection{Pengujian Struktur Mikro}

Pada pengujian struktur mikro digunakan mikroskop optik Olimpic dengan pembesaran 200X. Hasil struktur mikro untuk spesimen tanpa perlakuan dapat dilihat pada gambar 3.3. Hasil struktur mikro Tempering suhu $400^{\circ} \mathrm{C}$ pada gambar 3.4 , sedangkan Hasil struktur mikro Tempering suhu $500^{\circ} \mathrm{C}$ pada gambar 3.4 dan Hasil struktur mikro Tempering suhu $600^{\circ} \mathrm{C}$ pada gambar 3.5.

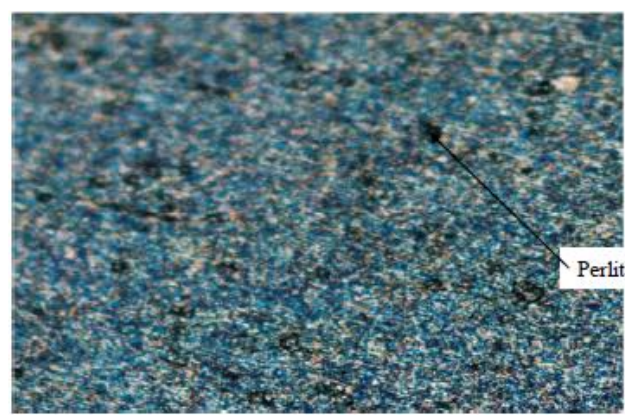

Gambar 3.3. Struktur Mikro BAJA AISI 4140 tanpa perlakuan

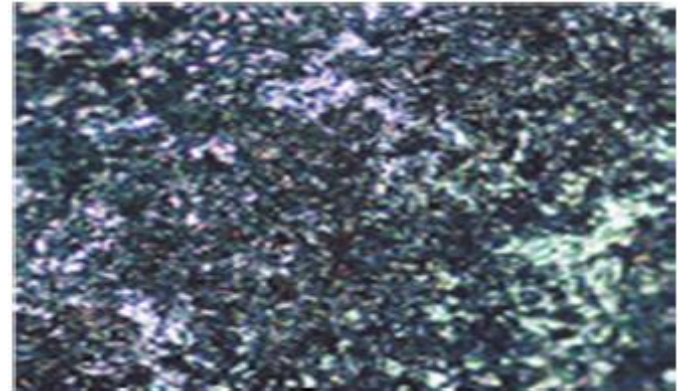

Gambar 3.4. Struktur Mikro BAJA AISI 4140 Tempering $300^{\circ} \mathrm{C}$ 


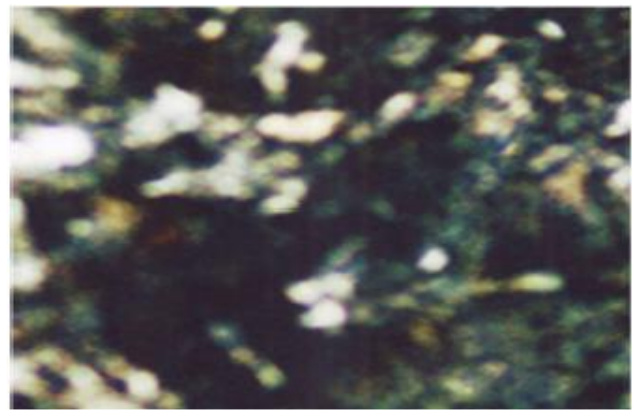

Gambar 3.5. Struktur Mikro BAJA AISI 4140 Tempering $400^{\circ} \mathrm{C}$

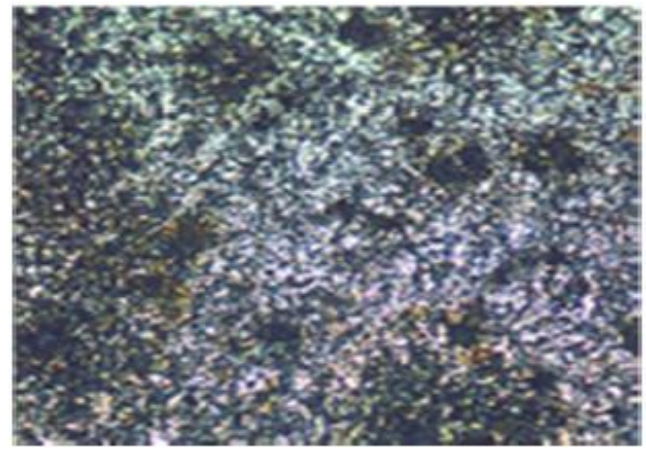

Gambar 3.6. Struktur Mikro BAJA AISI 4140

Tempering $500^{\circ} \mathrm{C}$

Pada pengujian struktur mikro digunakan mikroskop optik Olimpic dengan pembesaran 200X. Pada gambar dapat dilihat bahwa terdapat sisa $\gamma$ warna putih pada proses tempering. Semakin tinggi suhu tempering butiran sementitnya membulat, lebih halus dan besar dibandingkan yang tanpa perlakuan. Hal tersebut menyebabkan kekerasan baja AISI 4140 menurun dan keuletannya naik.

\section{KESIMPULAN}

Setelah dilakukan analisa terhadap hasil pengambilan data penelitian sifat mekanik Baja AISI 4140 yang telah mengalami tempering dan tanpa perlakuan, dapat kami simpulkan bahwa:

1) Terdapat penurunan kekerasan pada tiap kenaikan suhu tempering Baja AISI 4140, hal ini juga terlihat dari butiran hasil struktur mikro material yang membesar.

2) Terdapat kenaikan kekuatan tarik pada tiap kenaikan suhu tempering Baja AISI 4140, hal ini juga terlihat dari butiran hasil struktur mikro material yang membulat dan lebih halus.

\section{SARAN}

1) Perhatikan komposisi kimia material dan karakteristiknya dalam menentukan jenis perlakuan panas yang diberikan.

2) Dimensi benda uji harus diperhatikan dan disesuaikan dengan standar yang dijadikan acuan dalam pengujian material.

3) Pembuatan Spare Part mesin yang membutuhkan kenaikan kekerasan dan keuletan dapat menggunakan metode tempering, sehingga dicapai hasil yang sesuai dengan perhitungan perencanaan teknik.

\section{DAFTAR PUSTAKA}

[1] J. Jasman, S. Resmi, and U. Negeri, "Analisis Sifat Mekanik Dan Struktur Mikro Baja Aisi 4140 AKibat Perbedaan Temperatur Pada Perlakuan Panas Tempering," October, 2018.

[2] D. Perdana, "PENGARUH VARIASI TEMPERATUR PADA PROSES PERLAKUAN PANAS BAJA AISI 304 TERHADAP LAJU KOROSI," Tek. Eng. Sains J., 2017.

[3] A. Murtiono, "Pengaruh Quenching dan Tempering Terhadap Kekerasan dan Kekuatan Tarik serta Struktur Mikro Baja Karbon Sedang untuk Mata Pisau Pemanen Sawit," eDinamis, 2012.

[4] H. Anrinal, Metalurgi Fisik, First. Yogyakarta: Penerbit Andi, 2013.

[5] T. Sudira, Pengetahuan Bahan Teknik, Fourth. Jakarta: PT. Pradnya Paramita, 1999. 